\section{VIAGENS DE GEÓGRAFO}

\section{Lívia de Oliveira'}

HAESBAERT, Rogério. Por amor aos Lugares. Rio de Janeiro: Bertrand do Brasil, 2017, 317p. ISBN: 9788528622249

"Já Umberto Eco assinalava uma questão crucial: a cada leitor o escritor entrega uma mensagem privada. De fato o escritor só escreve metade do livro - a outra metade quem escreve é o leitor."

Paulo Nogueira. Uma sociedade anônima entre o autor e seus leitores. Aliás, 25/2/2018, p. 2.

Fazer uma resenha de um livro que lemos com prazer, interesse e ansiedade é tentar ser o leitor que procura a "outra metade de quem escreveu". Foi com curiosidade, em busca de alguma novidade, e principalmente, saber como o colega Rogério Haesbaert tratou, em suas andanças planetárias, suas crônicas "Por amor aos lugares".

Rogério e eu somos ambos, geógrafos e viajantes por esses mundos afora, porém em tempos diferentes. Minhas caminhadas foram há mais de 70 anos atrás, assim, foi com sofreguidão que percorri por todos os lugares conhecidos e desconhecidos. Senti-me sua companheira em muitos lugares. Apreciei paisagens, hospedei-me em conventos, pernoitei ao luar em desertos, dialoguei com transeuntes, encantei-me com a beleza do pôr-do-sol e me horrorizei com a miséria e a fome de muitos. Tudo isso me foi mostrado, com clareza e detalhes em seus périplos.

Os relatos, do autor, se iniciam com um prólogo: "1. O lugar como espaço que faz (a) diferença" ( $p$. 10-18). Deixo aqui as palavras explicativas:

Resta apenas, a partir de agora, o convite ao leitor para que acompanhe os relatos e imagens sem maior pretensão apenas se deixando levar pelos sentimentos e reflexões que, também por serem breves, estarão sempre abertas à reinterpretação de cada um (p. 17).

1 Professora Emérita da Universidade Estadual "Júlio Mesquita Filho" (UNESP). liviadeoliveira@yahoo.com.br. $\gtrsim$ Rua 1, n.705, apto.43, Rio Claro, SP. 13500-402.

Geograficidade | v.8, Número 1, Verão 2018 ISSN 2238-0205

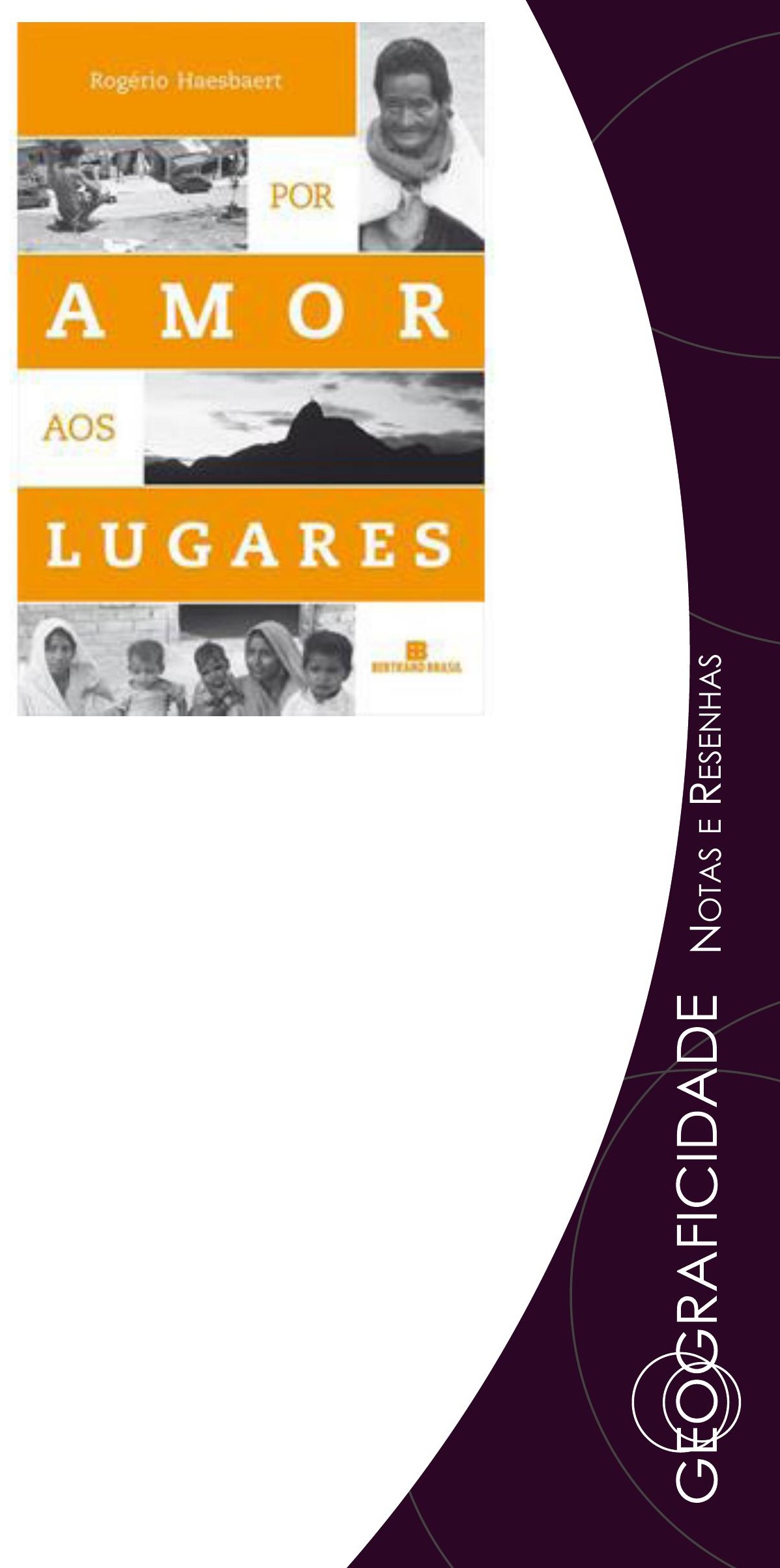


Mais adiante esclarece como organizou suas memórias e suas anotações:

começarei por lugares mais distantes, envolvendo viagens que marcaram pela força de suas diferenças, até chegar a espaços de vivência cotidiana e pretensamente mais seguros, os quais, nem por isso, mudando o olhar, estão alheios à surpresa e ao inusitado que instigam o questionamento e mudança (p. 18).

O título do segundo item é muito feliz, muito geográfico e muito significativo: "2. Lugares Viajantes" (p. 19-265), cobrindo a maior parte das páginas do livro. Os continentes percorridos foram: Ásia e África, seguida pela Europa e terminando pela América Latina.

A viagem começa pela fervilhante Índia (p. 19-48), com seu mosaico contrastante de espaços e de lugares pululando de pessoas, animais, veículos, religiões, sons e cores berrantes. Esta Índia "fascinante e assustadora ao mesmo tempo" (p. 24), foi percorrida pelo viajante Rogério, por várias cidades e regiões, tais como: Delhi, Jodhpur, deserto de Thar, Jaipur e outras.

Perambulou pela China (p. 49-62), indo de Pequim ao Tibete, passando pela Grande Muralha e as tumbas da dinastia Ming. "Pequim nos envolve pela imensidão de suas artérias com avenidas em trilha reta de até quarenta quilômetros e pelo fluxo humano, formigueiro que não para dia e noite, sem dúvida o maior espetáculo desta megalópole". (p. 49). Cruza regiões de Lanzhou e Xiahe "de uma incrivel diversidade geográfica, do deserto às florestas de coníferas" (p. 55).

Cortando o imenso platô tibetano, atingiu a cidade de Lhasa e teve "uma grata surpresa; descobriu o saboroso iogurte feito com leite de iaque" (p. 62). "Sob o efeito dessa paisagem sem limites, junto ao lago Turquesa (Yanhzo Yunco) escrevi: O Tibete se dilacera em pedaços de misérias que não separam nunca transpindadas pelos deuses e nesses despedaços sem fim viramos ilha [...]" (p. 65).

Esteve no Camboja e Vietnã (p. 68-110) visitando Ankor, a antiga capital do império Khmer. "O Camboja surpreende logo na chegada pela pobreza e pela quantidade de crianças pelas ruas" (p.69). No Vietnã nasce com detalhes a vida no delta do Mekong. Demora em descrever a cidade de Ho Chi Minh, antiga Saigon. Chama a atenção pela presença de motoqueiros. "Um bom capacete (muito raro de se ver pelas ruas) tem o mesmo valor de uma moto chinesa mais simples. A mais barata vale a bagatela de 200 dólares; as mais caras, por volta de quatro mil" (p. 77). Percorreu a baía de Ha Long, com uma visão fascinante e turística do mar e das ilhas. À velha Hanoi foi dado um destaque com visitas a templos e "ao suntuoso mausoléu de Ho Chi Minh, o Grande tio, como é conhecido pelos vietnamitas" (p. 109).

A grande surpresa é a viagem pela ilha de Madagascar (p. 111-136), tão emocionante quanto curiosa, essa ilha tão grande e misteriosa, A Madá, carinhosamente chamada pelos malgaxes. Os baobás e os lemures são grandes atrativos turísticos, junto com os rutilantes flamboyants (árvore nativa) e os arrozais irrigados. As cidades, a ferrovia, a pimenta e a baunilha são emblemáticas dos insulares.

Madagascar nos surpreende por todos os lados, mista de criatividade, solidariedade, exploração e miséria. Ali, aprendi a força de uma geografia de precariedade e do improviso, onde o provisório e o reaproveitamento emergencial acabam muitas vezes por se tornar a regra (p. 136).

Viajar pelo Egito e Jordânia (p. 137-158) é vislumbrar uma parte histórica, exótica e deslumbrante de nosso planeta habitado. Rogério nos chama atenção para: "Que sentido tem uma divisão física do 
mundo desse tipo que distingue África e Ásia dentro de um mesmo país?" (p. 137).

O realce é para o monastério Santa Catarina, um dos mais antigos, ainda, em atividade, "plantado no sopé do célebre Jebel Musa ou Monte Sinai, onde Moisés teria recebido as tábuas da lei [...]" (p. 141). No meio do deserto é um oásis, com jardins, pomares, olivais, um recanto de paz e de beleza.

A travessia do Mar Vermelho, a passagem por Aqba, chegando na Jordânia, até o vale da Lua, no Wachi Run, no deserto sul jordaniano: "é o local mais impregnado de significado para a geografia pessoal desta minha viagem" (p. 149). A misteriosa, simbólica e magnificente Petra é vista e revista de vários ângulos.

Na Europa (p. 159-200) são impressões pessoais e geográficas da Rússia, do Arquipélago dos Açores, de Hamburgo, de Londres e do País de Gales.

Na América Latina (p. 201-265) é um périplo por três países: México (p. 201-220) e Brasil (p. 239-265), com um interregno, com uma passagem emblemática por Cuba (p. 221-238).

No México é "difícil imaginar um povo para quem até a morte é santa e festejada. Haverá maior contradição do que isso?" (p. 206). 0 povo mexicano reverencia a morte. Aqui "parece que os opostos se encontram, ou melhor, já nasceram juntos" (p. 207).

Ao passo que "Cuba vive paradoxos. Vestígios de um velho mundo que permanece, esperança de outro mundo que não estabelece. Resquícios reais de uma geografia que 'parou no tempo!"' (p. 221).

Enquanto, no Brasil, o jalapão "terra de ninguém"; Sobral com sua "esquizofrenia de exceção"; e Roraima com o seu rio Branco, são todos tratados com muita propriedade e geograficidade.

"3. Lugares Cotidianos" (p. 267-317).

Nos caminhares pelas ruas cariocas, Rogério, vai colhendo, aqui e ali, instantâneos de "pontes de solidariedade, da luta pela Universidade Indígena, atento ao respeito pelo espaço público, ao oportunismo religioso" (p.267-282). Ao tratar das "geografias da tragédia" (p. 283288) ressalta, com sentimento e brio gaúchos, o ocorrido em Santa Maria. Somos lembrados que "no fundo, nada neste mundo é sem espaço. O mundo é espaço. Nossas vidas são espaços, exigem espaço, preenchem espaço, fazem espaço e se fazem como espaço. Não há saída sem espaço" (p. 286).

O autor termina seus "lugares viajantes", com Paris e sua geografia de Paris (p. 289-294) e com a chegada e a partida de Londres (p. 295317), colorindo com tons e sons, prenhes de sentimentos, de saudades, de vivência, e porque não dizer, com "amor aos lugares". () 